\title{
EL INTERNET COMO TRAMOYA DE LA CRISIS CIVILIZATORIA
}

\author{
Ramón Abraham Mena Farrera y Angélica Aremy Evangelista García \\ Departamento de Cultura y Sociedad de ECOSUR, México.rmena@ecosur.mx; aevangel@ecosur.mx
}

\begin{abstract}
Resumen. En la académica latinoamericana afrontamos la tarea de abordar los fenómenos sociotécnicos como nuevos retos comprensivos y metodológicos. Incursionamos en el estudio de las relaciones, prácticas y representaciones virtuales como procesos en donde los individuos, convertidos en consumidores en las redes de internet, pierden el contacto de manera acelerada con sus referencias ideológicas, sociales y de comportamiento, e intentan consumir otras ofertas de información global (Bauman, 2015). En esta ponencia reflexionamos los abordajes metodológicos para el estudio sociológico de ambientes digitales a partir de la experiencia en cuatro investigaciones sobre El hacktivismo e Internet como territorio en disputa (2019); Las prácticas de exclusión e inserción laboral en actividades productivas de turismo rural en dos comunidades transfronterizas de México y Guatemala (2020), El freelance. Espacios laborales en las redes sociales e internet. (2020) y El cuerpo situado en Grindr. Experiencias de la sexualidad gay en la interacción digital (2020) 1 .
\end{abstract}

Palabras clave: Metodologías Cualitativas en Ámbitos Digitales; Entornos Socio Digitales; Estudios de Género

\section{THE INTERNET AS A THEATRICAL STAGE OF THE CIVILIZATIONAL CRISIS}

\begin{abstract}
In Latin American academics, we face the task of approaching sociotechnical phenomena as new comprehensive and methodological challenges. We ventured into the study of relationships, practices and virtual representations as processes in which individuals, become consumers in Internet networks, rapidly lose contact with their ideological, social and behavioral references, and try to consume other offers of global information (Bauman, 2015). In this paper we reflect on the methodological approaches for the sociological study of digital environments based on the experience of four investigations on Hacktivism and the Internet as a disputed territory (2019); The practices of exclusion and labor insertion in productive activities of rural tourism in two cross-border communities of Mexico and Guatemala (2020), the freelance. Workspaces on social networks and the internet. (2020) and the body located in Grindr. Experiences of gay sexuality in digital interaction $(2020$
\end{abstract}

Keywords: Qualitative Methodologies in Digital Areas; Digital Partner Environments; Gender Studies

\section{INTRODUCCIÓN - EL DEBATE DE LOS ESTUDIOS SOCIOLÓGICOS Y METODOLOGÍAS CUALITATIVAS EN AMBIENTES DIGITALES}

Esta exposición parte de una premisa. Hoy presenciamos el debilitamiento de una sociedad occidental que da señales visibles en la crisis de representación política, la atomización de los movimientos sociales y gentrificación de las ciudades.

Lo que Amin Maalouf llama como "el naufragio de las civilizaciones" y en donde presenciamos, abro una la cita".

1 Los cuatro artículos son producto del debate académico de cuatro estudiantes con niveles de doctorado, maestría y licenciatura titulados en 2019 , en donde el ponente es el tutor. 
Cuando presenciamos espectaculares avances tecnológicos de nuestros días que nos han facilitado el acceso al conocimiento como nunca hasta ahora, que vivamos más y mejor, que el "tercer mundo" se desarrolle..., cuando por primera vez se podría conducir a la humanidad hacia una era de libertad y progreso, el mundo parece ir en dirección opuesta, hacia la destrucción de todo lo conseguido. ¿Cómo hemos llegado hasta aquí?" Amin nos invita a pensar cómo es que "nuestras civilizaciones se agotan" en "El desajuste del mundo" y en "Identidades asesinas", y aportaba las razones: la desconfianza hacia el "Otro", la xenofobia, la intolerancia política y religiosa, el populismo, el individualismo y la insolidaridad del nacionalismo, el racismo. Todo nos hace pensar que estamos inminentemente condenados al "naufragio inminente", en donde no hay añoranza de un pasado mejor, solo le preocupa el futuro de esta "época desconcertante", el porvenir de las nuevas generaciones, que pueda desaparecer lo que ha dado sentido a la aventura humana. Acaso debemos de darle vueltas al pesimismo, debemos predicar el desaliento, convocar a la responsabilidad colectiva, atrancar la puerta de la esperanza a que el mundo vuelva a orientarse. De lo que se trata, es advertir, que presenciamos una crisis civilizatoria sin precedente donde las relaciones que las sociedades sostienen ya no tienen un cimiento estable y es inminente que cambio del modelo y régimen político, social y económico. También se trata de que las academias, las iglesias, el Estado, las organizaciones, y los propios internautas, identifique a internet como uno de los espacios o ecosistemas en donde se discuten y se dinamizan las micro crisis sociales al interior de las instituciones.

Hoy en la academia somos responsables de advertir una inédita y poderosa alianza entre los datos, los algoritmos, el capital financiero y las relaciones sociotécnicas que establecemos todos en internet, la cual provoca constantes cambios en las regulaciones legales y la participación democrática de las sociedades en la red. Para la academia en Latinoamérica queda la tarea de estudiar los fenómenos sociotécnicos como nuevos retos comprensivos de relaciones, prácticas y representaciones virtuales las cuales se nutren del tiempo, el trabajo, el ocio y la vida de las personas, que pasan de ser ciudadanos a empleados con "libertades acotadas" por los nuevos tecno poderes económicos ejercidos por corporaciones como Airbnb, Google, Uber, y todas sus derivaciones. Por ejemplo, en el caso de la gentrificación, observamos en muchas ciudades europeas y latinoamericanas un rápido proceso económico en donde las personas, convertidos en consumidores en las redes de internet, pierden el contacto con sus referencias ideológicas, sociales y de 
comportamiento, transformándose en consumidores de la demanda y oferta del comercio digital.

En el caso particular, la academia mexicana libramos el reto de acompañar a los estudiantes a elaborar análisis cualitativos de fenómeno sociotécnicos de la resistencia. Se ha prestado poca atención al uso diario de las redes sociales como una herramienta para desafiar las relaciones desiguales de género, raciales, coloniales y económicas.

A inicios de la segunda década del siglo XXI, tenemos la obligación de acompañas y formar metodológicamente a jóvenes estudiantes con nuevos intereses de investigación, $m$ donde se comprendan y expliquen cómo se experimentan el debilitamiento de sociedad occidental, el debate de la crisis civilizatoria y la rápida transformación de ciudadano a consumidor es el marco del análisis de los resultados de cuatro investigaciones realizadas en 2018-2019, y publicadas en revistas académicas.

\section{EL RETO DE LAS METODOLOGIAS CUALITATIVAS EN INVESTIGACIONES EN AMBIENTES DIGITALES}

Los análisis a partir de análisis cualitativos en ambientes digitales tienen distintos matices a partir de los intereses particulares de los estudiantes. Aquí presentamos cuatro experiencias de investigación en los cuales se reconocen habilidades, intereses y posibilidades de usar metodologías para el análisis de novedosos temas de investigación, los cuales se presentan a continuación de manera sintetizada.

La primera investigación la titulamos "El hacktivismo e Internet como territorio en disputa" (2019); y abordamos a internet a partir de dos concepciones del territorio de internet, el primero como aquel en que se obtienen beneficios particulares relacionados a la dinámica económica global. El segundo a partir de una construcción de comunidades locales, muy ligadas al lugar y su circunstancia, en donde se defiendan la representación del territoriolugar digital como el espacio vivido, sentido y parte integrante de lo cotidiano, en donde se crean discursos y acciones en muchos casos, radicales en contra de la incursión de la globalización neoliberal.

La investigación presenta la forma en que los activismos tecnológicos encabezan luchas para tener mayor control de los datos de la población en el entorno digital. Por tanto, documentamos y analizamos la "autodefensa digital" y los "autocuidados digitales", términos que provienen de los ciberfeminismos y hackfeminismos. 
Analizamos eventos realizados en México como el Hackmitin (2017) como un espacio para compartir la formación digital en talleres, la difusión de materiales informativos y organizar la denuncia de abusos de poder, presentados desde las organizaciones que apelan a los derechos digitales. Hackmitin (2017) y otros foros dentro y fuera de la red de internet permitieron reaccionar en una importante movilización llamada \#GobiernoEspía encabezada por la ciudadanía que denuncio al Gobierno de México del presidente Peña Nieto (20122018) para que su administración detuviera sus prácticas invasivas de espionaje dirigido a los ciudadanos, líderes sociales, y periodistas independientes. Las acciones exigieron el derecho a la privacidad de la información de cualquier ciudadano en medios y plataformas digitales. El articulo ofrece evidencia de espacios y colectivos más autónomos, se enfocan más en las prácticas y herramientas de seguridad, creadas y difundirlas en la sociedad, y el trabajo constante y más lento de formación en espacios de internet y redes alternativas e independientes.

La segunda investigación se titula "Las prácticas de exclusión e inserción laboral en actividades productivas de turismo rural en dos comunidades transfronterizas de México y Guatemala" (2020) expone nuevas prácticas de exclusión e inserción laboral digital de las juventudes de dos comunidades rurales en la frontera de México con Guatemala con actividad ecoturística digital la cual es reconocida ya como una alternativa a la actividad agrícola y campesina.El trabajo documenta la manera en que la actividad turística crea nuevas oportunidades laborales, las cuales quedan subordinadas a las clásicas transversalizaciones de género, edad y raza a la cual se suma una coyuntural diferenciación más, la del conocimiento y uso de los ambientes digitales y acceso a internet en poblaciones rurales y campesinas. En el estudio se observa como los nuevos proyectos de la administración del presidente López Obrador (2018-2024) afectaran a las poblaciones en temas como el turismo, la migración y el uso de tecnologías en el sureste de México. Los proyectos de desarrollo de este gobierno ya tienen una fuerte oposición de las comunidades indígenas que no aceptaran que los proyectos de "desarrollo", "alto turismo", "explotación de recursos" y "proyectos ferroviarios y tecnológicos" atenten con el derecho de los pueblos originarios a ser consultados y que la decisión de instalar infraestructura que afecten a la Selva Lacandona y a la población indígena sean tomadas sin su opinión. Sin duda el internet es ya un espacio y una tribuna en donde las reuniones presenciales, los discursos, las consultas y los proyectos se gestionan en los mensajeros de WhatsApp. En los mensajes 
que el zapatismo envía por internet sostienen. "la devastación de la selva no los zapatistas, tumbaran las iniciativas con su resistencia y rebeldía.

La tercera investigación titulada: El trabajo y redes sociales: un análisis sociológico de los freelance (2020), el estudio aborda desde la sociología del trabajo uno de los fenómenos globales de mayor impacto en las juventudes que hoy trabajan y viven en las redes sociales, el freelance. Se explica cómo tras un largo proceso de crisis recurrentes en México derivada a 30 años de aplicación del modelo neoliberal en México, la juventud se replegó a múltiples precariedades, entre ellas la precariedad laboral. En el artículo se discuten el cambio del concepto de trabajo para los jóvenes y se analiza el impacto de las tecnologías y la creación de lo digital, permite un replanteamiento en la experticia laboral y económica de los jóvenes indígenas del sur de México. A partir una nueva sociología de la "tecnología en el trabajo", nos permite ver en concreto como funciona ya "la oficina andante" desde los celulares y los accesos gratuitos a internet en donde se experimentan "otra forma de pago", aquella relacionada al auto empleo. En la vida del joven freelans mexicano el trabajo no se diferencia del ocio, la vida privada, la recreación. Todo está revuelto en la época digital actual, y por consecuencia las nociones de la sociología del trabajo se deben replantear en medida que las redes sociales modifican el trabajo en espacios de internet creando una nueva estética del espectador que hoy depende del acceso y la interactividad. En este estudio se distingue como el joven responde ante la precarización del empleo como puede en las ciudades medianas, como la de san Cristóbal de Las Casas, la cual experimenta un rápido proceso se gentrificación en donde las aplicaciones móviles inician son claves para la renta de vivienda en la ciudad, servicios y un trabajo de mayor explotación.

Por último, el cuarto estudio titulado "El cuerpo situado en Grindr. Experiencias de la sexualidad gay en la interacción digital" (Monjaras \& Mena 2020), presenta una postura reflexiva del uso de las tecnologías digitales para el encuentro geolocalizado de hombres que practican experiencias homoeróticas en Grindr. La investigación discute el fenómeno desde la cultura-mundo, el sistema sexo-género-heteronormativo, la de-construccion de identidades estigmatizadas y lo especifico en el cruising virtual que reconfigura la gaycidad, y es co-producida desde la epistemológica fenomenológica tecnológica. Desde el debate queer se reflexiona la práctica y orgullo gay en los escenarios digitales, desde donde la sexualidad y el género trasgreden los márgenes de la norma y la hegemonía heteronormativa. Generar nuevos conocimientos, y cuestionamientos, de las experiencias de hombres en Grindr se gestó en reflexiones colaterales, y además comunitarias de sujetos 
intentando aprehender su estancia en la app de una manera autocrítica a través de la narración frente al otro, otro que era parte del mismo complejo de hombres gay ciborgs intentando resistir a las normas de la sexualidad, ayudándose de las aplicaciones como tecnologías del cuerpo. Lo comunitario -en sentido utópico- está presente a través de la resistencia de usuarios activistas o militantes de derechos LGBTTTIQ+ que con un enfoque distinto de sus cuerpos y su sexualidad se enfrentan a la heteronormatividad y homonormatividad, buscando generar una comunidad virtual -y no- de cuerpos libres que brinde y discuta información sobre género, derechos y salud, además de pensar-se- en una red que haga frente a situaciones de exclusión y violencia que viven en la actualidad en la ciudad de San Cristóbal de Las Casas.

Las reflexiones que surgieron en el camino tienen que ver con lo cotidiano que llega a ser para nosotros habitar una pantalla y amoldarse a sus estructuras, siguiendo patrones que no se cuestionan, solo se asimilan, creando entonces comportamientos compulsivos en los que hay muy poco de una verdadera interacción en la que se tenga en cuenta al otro. Sobre todo, pensando que el sexo se trata del cuerpo, de intimidad y de conexión que va más allá de lo físico sería bueno preguntarnos si ¿queremos seguir generando nuestras vivencias sexuales como comportamientos compulsivos? O empezar a pensar en relaciones de cuidado y afecto a través de los cuerpos, de todo tipo de cuerpos

Para concluir los cuatro estudios presentados analizan con innovadoras propuestas metodológicas en la arena de lo digital la lucha, la resistencia, el enfrentamiento y la precariedad de la juventud mexicana, en los ambientes digitales actuales desde México. Los retos los enfrentan jóvenes en lo colectivo, lo queer, lo transnacional y lo individual. El reto para la academia es mayúsculo, entrar a la red de internet y hacer estudios espanta a una generación de antropólogos, sociólogos, economistas y nuestra tarea es ir junto con los estudiantes.

Por último, estos estudios se desarrollaron desde la misma ciudad desde donde se hace 26 años el Ejercito Zapatista de Liberación Nacional, (EZLN) público en desde un portal de internet uno de los primeros mensajes de rebeldía y cambio en las redes: "El cambio que queremos es que un día el pueblo, mujeres y hombres, sean los que tengan que decidir cómo quieren su vida, no que un grupo decida la vida de millones de seres humanos. Lo decimos solo con estas palabras: el pueblo manda, y el Gobierno obedece" 


\section{REFERENCIAS}

Guilluy, C. (2019) No society: El fin de la clase media occidental. Taurus. Madrid.

Lassalle, J, M. (2019) Ciberleviatán: El colapso de la democracia liberal frente a la revolución digital. Arpa. Madrid.

Bauman. Z. (2015) Los Retos De La Educación En La Modernidad Líquida, Gedisa editorial. Madrid

Lechón, D.; Mena, R. (2019) El hacktivismo e Internet como territorio en disputa. Revista Estudios Políticos. UNAM.

Ramos, D.; Mena. R. Ramos, D. Castañeda, (2020). Prácticas de exclusión e inserción laboral en actividades productivas de turismo rural, en dos comunidades transfronterizas de México y Guatemala. Revista El Periplo Sustentable. (EN PRENSA)

Cruz, A.; Mena. R. (2020) El freelance. Espacios laborales en las redes sociales e internet. Revista Región y Sociedad de El Colegio de Sonora (EN DICTAMEN)

Monjaras, R. Mena R. (2020). El cuerpo situado en Grindr. Experiencias de la sexualidad gay en la interacción digital. Revista Interdisciplinaria de Estudios de Género de El Colegio de México. (EN DICTAMEN) 